\title{
PROSÓDIA E CONSTRUÇÃO DE ETHÉ DISCURSIVOS EM CRIMES VIA TELEFONE
}

\author{
PROSODIA Y LA CONSTRUCCIÓN DEL ETHÉ DISCURSIVO EN DELITOS PRACTICADOS A \\ TRAVÉS DEL TELÉFONO
}

PROSODY AND DISCURSIVE ETHÉ CONSTRUCTION IN TELEPHONE CRIMES

\author{
Welton Pereira e Silva* \\ Universidade Federal do Rio de Janeiro \\ Mônica Santos de Souza Melo** \\ Universidade Federal de Viçosa \\ Rony Petterson Gomes do Vale ${ }^{* * *}$ \\ Universidade Federal de Viçosa
}

\begin{abstract}
RESUMO: Este trabalho objetiva apresentar a forma como determinadas características suprassegmentais, relacionadas à prosódia, podem contribuir para construção e manutenção de certos ethé discursivos, que visam a legitimar o sujeito argumentante. Baseamos a análise do corpus no referencial teórico e metodológico da Teoria Semiolinguística do Discurso (CHARAUDEAU, 2012, 2015), bem como em Perelman e Tyteca (2005). O corpus é constituído por duas gravações telefônicas de golpes do falso sequestro e uma gravação de golpe da recarga premiada. Após a análise do material empírico, notamos que certas marcas prosódicas, como o ritmo e a entonação, podem contribuir para a constituição do ethos de potência por parte do criminoso, bem como para a construção do ethos de competência. A construção do ethos, da imagem de si, através do discurso, é uma forma de o sujeito argumentante garantir a legitimidade para sua pessoa e a credibilidade para seus argumentos.
\end{abstract}

PALAVRAS-CHAVE: Prosódia. Ethos discursivo. Argumentação.

RESUMEN: Este artículo tiene como objetivo presentar como ciertas características suprasegmentales relacionadas con la prosodia pueden contribuir a la construcción y mantenimiento de ciertos ethe discursivos destinados a legitimar el sujeto que habla. Basamos el análisis del corpus en la Teoría Semiolingüística del Discurso (CHARAUDEAU, 2012, 2015), así como en Perelman y Tyteca (2005). El corpus se compone de dos grabaciones de los "golpes do falso sequestro" y una grabación de "golpe da recarga premiada". Tras el análisis del material empírico, observamos que ciertas marcas prosódicas, como el ritmo y la entonación, pueden contribuir a la formación del ethos de potencia por el criminal, así como en la construcción del ethos de competencia. La construcción del

\footnotetext{
* Doutorando em Letras Vernáculas - Língua Portuguesa pela na Universidade Federal do Rio de Janeiro. Mestre em Letras - Estudos Linguísticospela Universidade FederaldeViçosa. E-mail: weltonp.silva@hotmail.com.

** Doutora em Estudos Linguísticos pela Universidade Federal de Minas Gerais. Professora Associada IV da Universidade FederaldeViçosa. E-mail: monicassmelo@yahoo.com.br.

*** Doutor em Linguística do Texto e do Discurso pela Universidade Federal de Minas Gerais. Professor Adjunto da UniversidadeFederal deViçosa. E-mail: ronyvale@gmail.com.
} 
ethos, la imagen de sí mismo a través del discurso, es una forma para que el sujeto garantice la legitimidad de su persona y la credibilidad de sus argumentos.

PALABRAS CLAVE: Prosodia. Ethos discursive. Argumento.

ABSTRACT: This study aims to present how certain suprasegmental characteristics related to prosody can contribute to the construction and maintenance of certain discursive ethé that seek to legitimatize the subject that argues. We based the analysis of the corpus on the theoretical and methodological framework of the Theory Semiolinguistics of Discourse (CHARAUDEAU, 2012, 2015) and Perelman and Tyteca (2005). The corpus consists of three phone records originating from fake kidnapping strokes and a recording of prizewinning cellphone recharge. After the analysis of the empirical material, we noted certain prosodic brands such as rhythm and intonation may contribute to the formation of ethos of potency by the criminal, as well as the construction of the ethos of competence. The construction of the ethos is a way that the subject ensures legitimacy for his person and credibility to their arguments.

KEYWORDS: Prosody. Discursive Ethos. Argumentation.

\section{INTRODUÇÃO}

O presente trabalho é oriundo de uma pesquisa de mestrado, realizada no Programa de Pós-Graduação em Letras da Universidade Federal de Viçosa, com o apoio da Capes. O objetivo dessa pesquisa foi procurar entender a forma como os criminosos constroem seus argumentos de modo a convencer as vítimas acerca da veracidade de suas informações, em dois tipos de crimes praticados através do telefone: os golpes do falso sequestro e os golpes da recarga premiada. A pesquisa, portanto, vincula-se à Linguística Forense, por tentar entender o funcionamento argumentativo no interior de duas práticas criminosas distintas.

Neste artigo, em particular, procuraremos demonstrar que determinadas características linguísticas, relacionadas à prosódia, portanto, de natureza suprassegmental, podem contribuir para construção e manutenção de determinados ethé discursivos. O ethos pode ser entendido como a imagem construída pelo sujeito, que argumenta através de seu discurso. Essa imagem é construída visando a garantir a legitimidade do argumentante e a credibilidade a seus argumentos.

Dessa forma, na primeira parte deste manuscrito, apresentamos a noção de ethos na Teoria Semiolinguística, entendendo a argumentação sob o ponto de vista da Nova Retórica. Além disso, nessa parte, discorremos a respeito de nosso corpus de pesquisa, constituído por dois diferentes gêneros. Posteriormente, na seção dois, apresentamos algumas ideias concernentes ao auxílio de determinadas marcas prosódicas na construção de ethé. Por fim, na terceira parte, procuramos demonstrar, através de algumas análises auxiliadas com recurso ao software $\mathrm{PRAAT}^{1}$, um programa de análise acústica, que determinadas marcas prosódicas podem ser determinantes na construção, na manutenção e mesmo na descronstrução de certas imagens discursivas.

\section{A NOÇÃO DE ETHOS DISCURSIVO NA TEORIA SEMIOLINGUÍSTICA}

Na obra clássica intitulada Retórica, Aristóteles apresentou-nos três espécies de provas artísticas através das quais o orador pode embasar seus argumentos. Dentre essas provas, o ethos era aquela relacionada ao caráter do orador, sua ascendência familiar, seu modo de se vestir, sua fama na pólis etc. Ou seja, o ethos contribuiria para que os argumentos do orador fossem credíveis ou legitimados pelo fato de serem proferidos por alguém que detinha a legitimidade e a credibilidade adequadas. Para Aristóteles (2005, p. 96):

Persuade-se pelo carácter quando o discurso é proferido de tal maneira que deixa a impressão de o orador ser digno de fé. Pois acreditamos mais e bem mais depressa em pessoas honestas, em todas as coisas em geral, mas sobretudo nas de que não há conhecimento exacto e que deixam margem para dúvida. É, porém, necessário que esta confiança seja resultado do discurso e não de uma opinião prévia sobre o carácter do orador; pois não se

\footnotetext{
${ }^{1}$ O PRAAT é um programa de análise de voz desenvolvido por Paul Boersma e David Weenink, ambos do Institute of Phonetic Sciences da Universidade de Amsterdam. O programa pode ser obtido gratuitamente através do site oficial: <www.praat.org $>$.
} 
deve considerar sem importância para a persuasão a probidade do que fala, como aliás alguns autores desta arte propõem, mas quase se poderia dizer que o carácter é o principal meio de persuasão.

Já recentemente, os estudos em argumentação, nomeadamente no âmbito das teorias da Análise do Discurso, voltaram seu interesse para a noção aristotélica de ethos, mas adaptando-a. Agora, o ethos passaria a ser a imagem de si construída pelo orador através de seu discurso, ou seja, como ele se mostra, como ele formula seus enunciados para garantir a adesão do público destinatário de seu argumento.

Para certos autores, como Maingueneau (2008) e Charaudeau (2015), certas questões relativas à vida social do orador também contribuem para a consolidação dessa imagem discursiva. Assim, no presente estudo, filiamo-nos aos postulados teóricos e metodológicos da Teoria Semiolinguística do Discurso, proposta por Patrick Charaudeau, para quem:

O ethos relaciona-se ao cruzamento de olhares: olhar do outro sobre aquele que fala, olhar daquele que fala sobre a maneira como ele pensa que o outro o vê. Ora, para construir a imagem do sujeito que fala, esse outro se apoia ao mesmo tempo nos dados preexistentes ao discurso - o que ele sabe a priori do locutor - e nos dados trazidos pelo próprio ato de linguagem. (CHARAUDEAU, 2015, p. 115)

Dessa forma, podemos notar que, para a Semiolinguística, a imagem discursiva do sujeito que argumenta é corroborada pela identidade social deste mesmo sujeito. Sobre as noções de identidade social e identidade discursiva, Charaudeau (2009) esclarecenos que a identidade social seria formada pelas características biológicas e sociais do sujeito, estando relacionada a sua legitimidade, seu "direito à palavra". É interessante ressaltar que essa identidade social pode ser mascarada ou alterada pelo sujeito em seu discurso. Por sua vez, a identidade discursiva depende das estratégias da credibilidade e de captação e pode ser entendida como a identidade construída pelo sujeito em seu próprio discurso.

Relacionada, então, à identidade social e à identidade discursiva, a noção de ethos nos remete à imagem construída pelo sujeito através do que ele diz, visando a atender às estratégias discursivas da credibilidade e da legitimidade. Através da primeira, o sujeito enunciador - ou seja, o sujeito projetado no discurso - tenta garantir que o sujeito destinatário, seu interlocutor ideal, acredite em suas palavras. Através da estratégia da legitimidade, esse sujeito procura mostrar-se como legitimidado, detentor do "direito à palavra”, já mencionado acima. Essas estratégias são utilizadas devido ao princípio da influência da troca comunicativa, já que, em todo ato linguageiro, o sujeito enunciador procura influenciar seu destinatário. Podemos perceber, então, que a Semiolinguística entende que o processo argumentativo pressupõe a adesão do sujeito destinatário, o auditório do sujeito que argumenta. Esse é o princípio norteador da Nova Retórica, proposta por Perelman e Tyteca (2005, p.50), que explicam-nos que o objetivo da argumentação consiste em "[...] provocar ou aumentar a adesão dos espíritos às teses que se apresentam a seu assentimento: uma argumentação eficaz é a que consegue aumentar essa intensidade de adesão, de forma que se desencadeie nos ouvintes a ação pretendida (ação pretendida ou abstenção) ou, pelo menos, crie neles uma disposição para a ação, que se manifestará no momento oportuno.".

No presente trabalho, conciliamos a visão teórica da Nova Retórica ao que a Semiolinguística apresenta-nos acerca da prática argumentativa. Assim, veremos, a partir da análise do nosso corpus nas próximas seções, que certas particularidades linguísticodiscursivas são também cruciais para a construção e, principalmente, para a manutenção de determinados ethé, que visam à adesão do auditório. Desse modo, além do conteúdo proposicional do ato discursivo, o sujeito pode lançar mão, por exemplo, de certos recursos de natureza prosódica para corroborar a imagem que ele deseja construir de si mesmo. Dentre esses recursos, veremos que alguns parecem ser conscientes, enquanto outros parecem fazer parte da natureza da linguagem e do discurso.

Para a realização desta pesquisa, debruçamo-nos sobre a análise de dois textos oriundos de gravações telefônicas referentes ao crime conhecido como golpe do falso sequestro e um texto oriundo de uma interação relativa aos chamados golpes da recarga premiada. A escolha do material se deu pelo fato de os dois tipos de golpes serem efetuados, principalmente, através da interação telefônica, portanto, do discurso. No primeiro tipo de golpe, os criminosos fazem uma ligação aleatória e, ao serem atendidos, afirmam estar em posse de um familiar da pessoa que atendeu a ligação. Assim, eles procuram convencer a possível vítima a efetuar o pagamento 
do falso resgate e, caso ela acredite em suas palavras, poderá efetuar o pagamento e consumar o crime. Nos golpes da recarga premiada, por sua vez, após receber uma mensagem SMS, caso a possível vítima efetue a ligação solicitada na mensagem, é atendida por um criminoso que se passa por um representante comercial de uma empresa, que entregaria o suposto prêmio à vítima. Através de argumentos que simulam uma ligação de telemarketing, caso o sujeito que efetuou a ligação não perceba o teor falacioso da interação, poderá transferir uma determinada quantia monetária para uma conta bancária fornecida pelos criminosos.

As gravações dos golpes do falso sequestro foram conseguidas pela Polícia Civil do Rio de Janeiro e disponibilizadas pela Revista Veja na modalidade online. A gravação do golpe da recarga premiada, por sua vez, foi obtida a partir do site You Tube. Após a audição exaustiva de cada interação, foi realizada a transcrição do conteúdo linguístico de modo a tornar mais viável a análise, que poderá ser vista na terceira seção deste trabalho.

\section{PROSÓDIA E ETHOS: MARCAS ACÚSTICAS E CONSTRUÇÃO DA IMAGEM DISCURSIVA}

No presente estudo, compartilhamos do pensamento de Maingueneau (2000), para quem a Análise do Discurso não deve abster-se de procurar dialogar com as demais disciplinas linguísticas. Para ele: "Embora a análise do discurso, por sua própria natureza, se encontre num cruzamento de ciências sociais, e embora os analistas do discurso se interessem pelo discurso por razões filosóficas ou sociológicas, penso que a análise do discurso deve manter sua relação privilegiada com a linguística." (MAINGUENEAU, 2000, p. 4).

Levando-se em conta que o discurso é construído, de modo basilar, pelo uso que diferentes sujeitos fazem da língua em determinado contexto sócio-histórico, tentaremos mostrar que, mesmo o nível fonético com seus aspectos suprassegmentais, pode contribuir para a construção dos sentidos negociados pelos sujeitos que participam de um ato de linguagem, analisando algumas construções de imagens de si que são auxiliadas por recursos prosódicos.

Algumas características acústicas da fala podem dar certas pistas a respeito da idade, da procedência geográfica, do gênero e mesmo do estado emocional do sujeito falante. Essa possibilidade é utilizada por pesquisadores da Fonética Forense que, auxiliados pela Sociolinguística Variacionista, podem construir o perfil linguístico de um determinado locutor. Observemos o que dizem-nos Foulkes e French (1999, p. 329, tradução nossa):

Uma combinação de análises fonéticas e sociolinguísticas podem ajudar a estabelecer informações sobre o ‘background' do falante. Os perfis linguísticos dos falantes são regularmente requisitados nos estágios iniciais de sequestros, onde uma gravação da voz do sequestrador pode ser a única pista de sua identidade. Podem ser recolhidas informações acerca do sexo, idade, procedência geográfica e posição social do falante, bem como algumas idiossincrasias como desordens de fala.

Percebemos, então, que certas marcas de natureza acústica podem nos fornecer pistas acerca da identidade social do sujeito que argumenta. Neste artigo, tentamos avançar um pouco mais nessas reflexões e entendemos que, assim como as características acústicas de um determinado enunciado podem transmitir algumas pistas individuais de um falante, certas marcas prosódicas e, portanto, também acústicas, podem ajudar na construção da identidade discursiva que o locutor deseja demonstrar. Ou seja, essas marcas prosódicas podem servir como auxílio na construção do ethos, conforme mostram-se, direta ou indiretamente, Charaudeau (2015), Maingueneau (2008) e Galinari (2011).

Em Charaudeau (2015), encontramos o procedimento expressivo do "falar forte" e do "falar tranquilo" que, para o autor, auxiliam na construção de ethé políticos relacionados ao poder, à liderança combativa no caso do "falar forte" e a uma imagem de inteligente, de chefe, de alguém dotado de caráter no caso do "falar tranquilo". Ambos os procedimentos expressivos são formados pela combinação do ato discursivo com elementos extralinguísticos, como a vestimenta, o porte, a decoração do ambiente. 
No que diz respeito à enunciação em si, Charaudeau (2015, p. 172) afirma que o "falar forte" é evocado com a utilização da voz "bem timbrada, capaz de ocupar um grande auditório com ressonância” e com a utilização de uma dicção relativamente acelerada, mas com uma pronúncia bem articulada. Já o falar tranquilo se caracteriza "por uma dicção lenta, mas acompanhada de um tom de voz que não é nem terno nem estrondoso". Podemos observar que, para Charaudeau, ao lado de questões de diversa natureza linguística ou extralinguística, elementos de natureza prosódica como o tom de voz e o ritmo contribuem para construção e elaboração do ethos discursivo. Já Maingueneau (2008) deixa claro que o tom de voz seria um dos componentes do que ele chama de ethos mostrado.

Além de Charaudeau (2015) e Maingueneau (2008), baseamo-nos em Galinari (2011), para quem "a estrutura prosódica, por exemplo, enquanto logos-rítmico, é capaz de construir, durante a enunciação, alguma imagem de seu emissor (ethos) e/ou suscitar emoções nos interlocutores (pathos)" (GALINARI, 2011, p. 102, grifos do autor). Assim, vemos que, para esse autor, certas estruturas prosódicas também podem auxiliar na construção da imagem do emissor, embora estejam relacionadas ao logos.

A respeito da prosódia, esta pode ser entendida como o estudo da maneira como as propriedades relativas aos sons (intensidade, altura e duração) funcionam nas línguas orais em geral (MATEUS et al., 2005, p.240, grifos no original). Dessa forma,

De um ponto de vista fonológico, as línguas utilizam essas propriedades com objectivos diversos: (i) para marcar os limites das unidades (o acento pode indicar o fim ou o início da palavra; a curva de entoação pode igualmente marcar os limites de unidades prosódicas); (ii) para criar oposições distintivas (nas línguas tonais, o tom de uma sílaba, por contraste com os tons das que a rodeiam, pode opor significados entre duas palavras cujos segmentos são iguais tendo, assim, uma função distintiva); (iii) para distinguir significados globais de construções frásicas (a entoação é usada frequentemente para diferenciar uma interrogação de uma afirmação, por exemplo).

Observamos, portanto, que as características referentes à intensidade, à altura e à duração de um determinado enunciado poderão servir como pistas que ajudam o interlocutor a compreender de forma mais adequada o enunciado proferido pelo locutor. Assim, a utilização desses marcos linguísticos auxilia no processo de produção do ato de linguagem, desde o caráter distintivo em línguas tonais até a ajuda em questões semânticas e pragmáticas (como reconhecer uma ordem, um pedido, uma pergunta). Baseando-nos nesse ponto de vista, podemos perceber que a intensidade, a altura e a duração de determinados elementos do enunciado podem auxiliar os participantes de uma determinada situação de comunicação a alcançarem seus objetivos comunicativos através, principalmente, de estratégias discursivas atreladas ao ethos.

Para explicar essas ideias de forma mais adequada, na próxima seção, apresentamos a análise de determinados ethé discursivos construídos por criminosos, visando a persuadir as possíveis vítimas dos crimes via telefone aqui analisados.

\section{CARACTERÍSTICAS PROSÓDICAS E ETHOS EM CRIMES VIA TELEFONE}

Começaremos a explicar o posicionamento anteriormente explicitado, a partir da análise de um determinado momento em um dos textos do nosso corpus, no qual ocorre uma situação em que o sujeito argumentante, passando-se por um sequestrador que liga para uma mãe de modo a negociar o pagamento de um resgate relativo ao suposto sequestro de sua filha, recorre ao uso de um vocábulo proferido em tom mais elevado, de modo a demonstrar uma possível insatisfação com o rumo tomado pela negociação. As letras em caixa alta representam a intensidade elevada do tom de voz:

a) Olha só, se a senhora não querer negociar, eu vou desligar o telefone e vou matar a sua filha, PORRA!

Em uma análise da natureza acústica desse trecho, obtido com recurso ao programa PRAAT, podemos observar o contraste entre a intensidade dos elementos que compõem o enunciado, contraste perceptível através da linha amarela que demonstra os contornos da intensidade no decorrer do tempo (aproximadamente cinco segundos): 


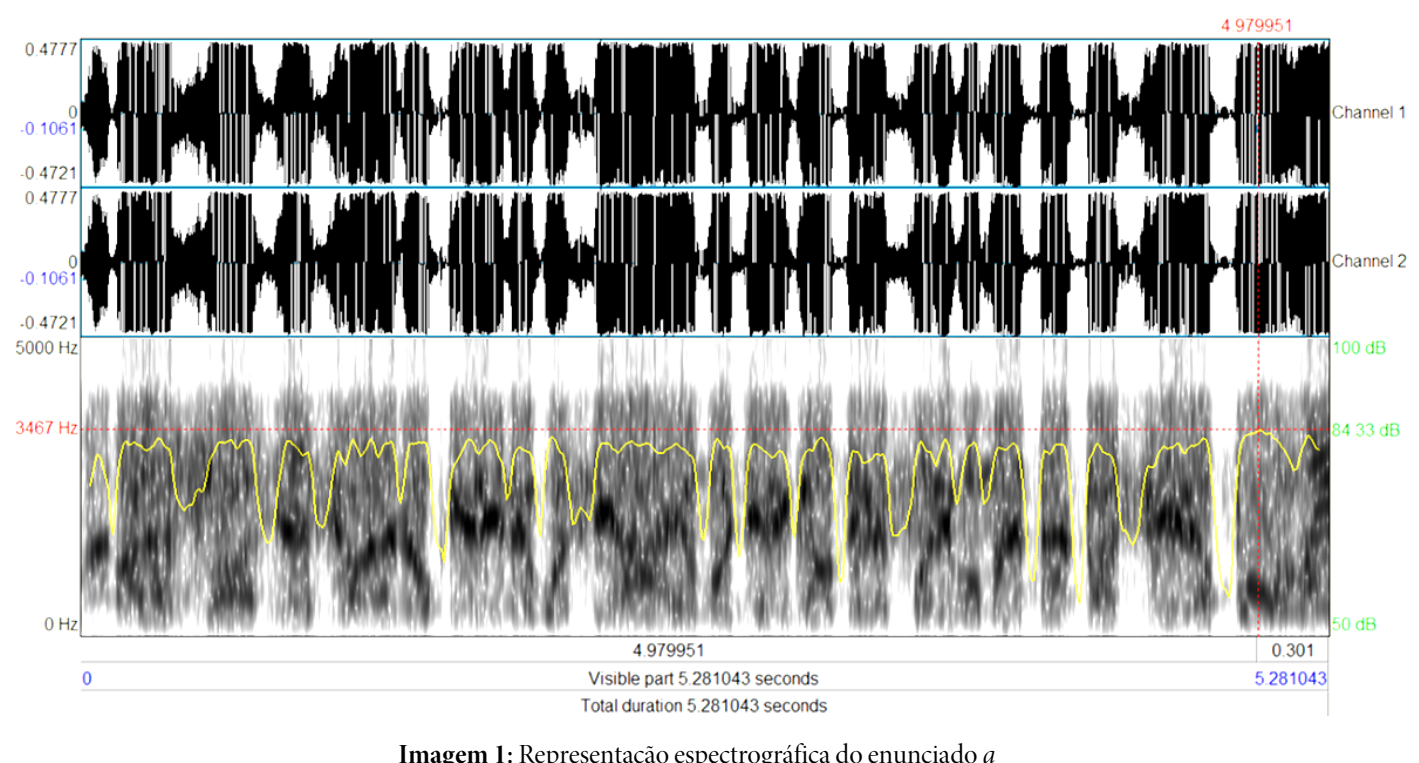

Fonte: dados dos pesquisadores.

Devido ao fato de o espectrograma representar o sinal acústico produzido ao longo do tempo, a leitura da imagem deve ser feita na horizontal, da esquerda para a direita. Conforme ensinam-nos Mateus et al. (2005, p.114),

No espectrograma encontram-se contempladas três dimensões do sinal acústico: tempo, frequência e amplitude. O tempo, em segundos (ou em milissegundos), encontra-se no eixo horizontal e a frequência, em hertz, no eixo vertical. A amplitude do sinal é dada por uma gradação de tons de cinzento: as zonas mais escuras são zonas de maior amplitude (e, consequentemente, de maior intensidade auditiva.

Assim, no eixo vertical, encontram-se as taxas de frequência da onda sonora, enquanto que, no eixo horizontal, encontra-se a evolução do sinal acústico ao longo do tempo. Os ruídos são representados pelas linhas verticais escuras e, em relação às pausas, a falta de sinal acústico acaba por gerar uma lacuna em branco. Assim, podemos observar que o último grupo de força, referente ao lexema "porra", pronunciado após a última coluna branca, é proferido com uma intensidade mais elevada quando comparado aos elementos que o antecedem, conforme pode ser visto com o auxílio da linha amarela horizontal, que assinala o contorno da intensidade, e pelo número em verde à direita da imagem, que representa o valor em decibéis atingido pela produção acústica $(84,33$ $\mathrm{dB})$.

Dessa maneira, notamos que, ao fazer uso desse vocábulo proferido de forma enfática, agindo violentamente, o criminoso parece não querer deixar dúvidas acerca de sua insatisfação em relação à vítima, que dizia não ter como negociar com ele. O locutor faz uso desse tom mais elevado após fazer uma ameaça. A não negociação do pagamento do falso resgate por parte da vítima teria como consequência a execução da filha supostamente sequestrada. Esse argumento patêmico, que corrobora o ethos de potência - um criminoso cruel, violento, capaz de cumprir com suas ameaças -, por sua vez, é auxiliado pelo recurso prosódico da intensidade elevada efetuada por parte do criminoso. O vocábulo dito de forma enfática pode ter servido, dados seus sentidos extralinguísticos, para corroborar o ethos ameaçador do criminoso, além de auxiliar na obtenção do objetivo de despertar o terror na vítima.

É interessante notar que, durante o percurso interativo nos golpes do falso sequestro, é na fase que foi chamada de negociação (SILVA; MELO, 2015) que surgem enunciados proferidos com uma intensidade mais elevada, conforme podemos observar, por exemplo, na Imagem 2: 


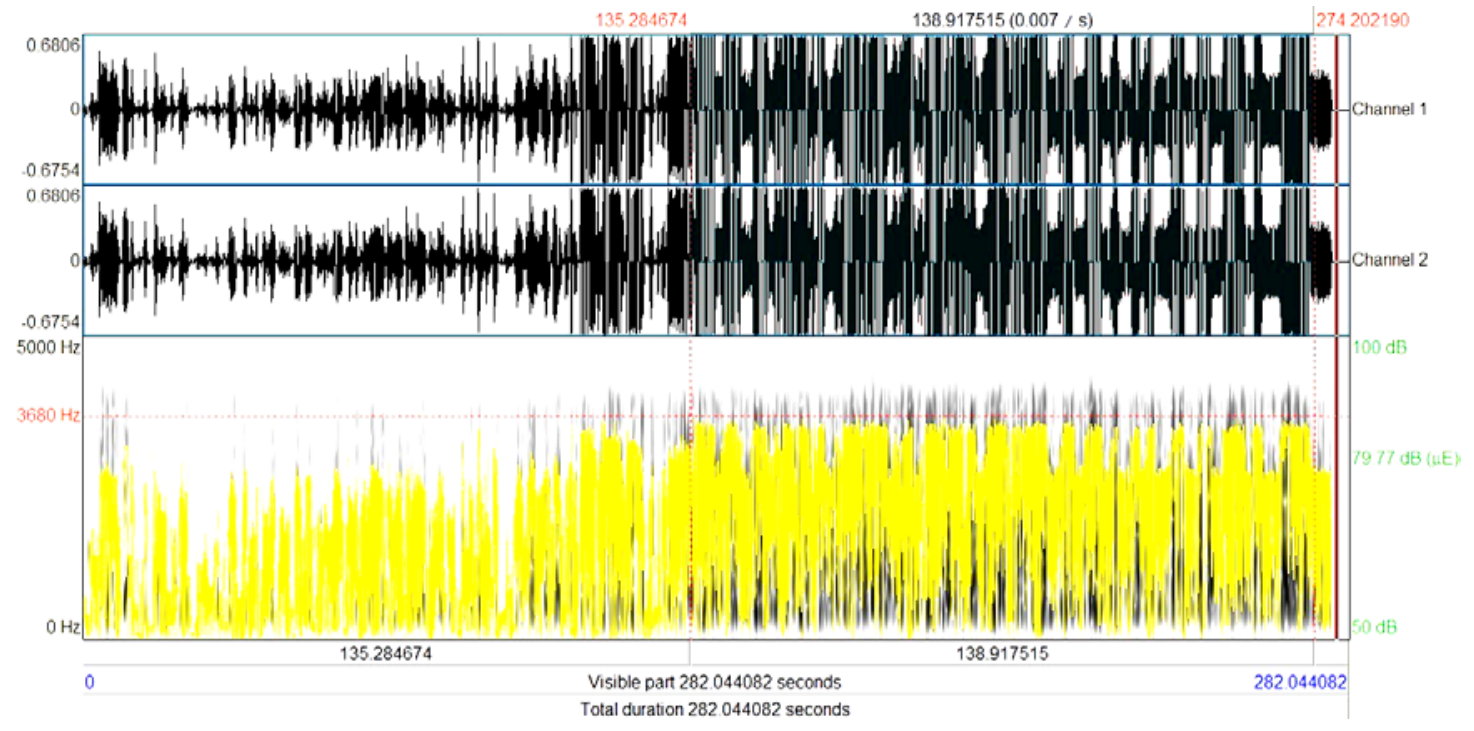

Imagem 2: Representação espectrográfica da intensidade durante a fase de negociação

Fonte: dados dos pesquisadores.

De acordo com Silva e Melo (2015), o modus operandi do gênero golpe do falso sequestro consiste em quatro fases distintas: a abordagem, a revelação do sequestro, a negociação e o desfecho. Essas fases correspondem, igualmente, ao formato relativamente estável desse gênero discursivo. É durante a fase de negociação que acontece o clímax da interação, no qual os criminosos fazem uso de diversos argumentos, visando a convencer a vítima a efetuar o pagamento do falso resgaste.

Quanto à Imagem 2, ela representa toda a interação discursiva encontrada em um dos textos pertencente ao nosso corpus. Devido a isso, um número maior de dados acústicos foi registrado pelo espectrograma, fazendo com que a marcação de intensidade, em amarelo, ficasse mais saliente quando comparamos essa imagem à anterior, que representou apenas uma parte da interação, aproximadamente cinco segundos, enquanto esta última imagem representa toda a interação, com aproximadamente quatro minutos de duração. O tempo registrado pelo programa é calculado em segundos, no caso, o espectrograma representa duzentos e oitenta e dois segundos, aproximadamente.

A partir da análise dos dados presentes no espectograma da Imagem 2, portanto, podemos observar que, ao ser indagado sobre a localização do suposto sequestrado, dando início à fase de negociação através de ameaças, o criminoso produz enunciados possuidores de uma intensidade mais acentuada, conforme podemos perceber através das oscilações em amarelo no espaço delimitado pela cor rosa, correspondente a aproximadamente cento e trinta e nove segundos da interação telefônica. Na fase de negociação, como já dissemos anteriormente, ocorre a maior parte das ameaças, bem como a utilização de argumentos patêmicos e construções de ethé, dentre eles, o de potência que pode ser auxiliado com o procedimento expressivo do falar forte, relacionado à intensidade prosódica.

Além desses usos no que diz respeito ao tom, à entonação e à intensidade, podemos perceber que toda a negociação efetuada no gênero aqui chamado de Golpe do Falso Sequestro é construída com enunciados proferidos em um ritmo acelerado. A própria natureza da situação de comunicação exige que o sujeito comunicante, o criminoso, aja de forma rápida, de modo a fazer com que a vítima não tenha tempo de refletir acerca da situação de comunicação na qual está inserida. Dessa forma, durante todo o percurso interacional, o criminoso fala rapidamente, produzindo seu discurso em um ritmo mais acelerado do que o que encontraríamos em uma conversa cotidiana, ordinária. Observemos, a fim de ilustração, os dados representados no espectrograma da Imagem 3 : 


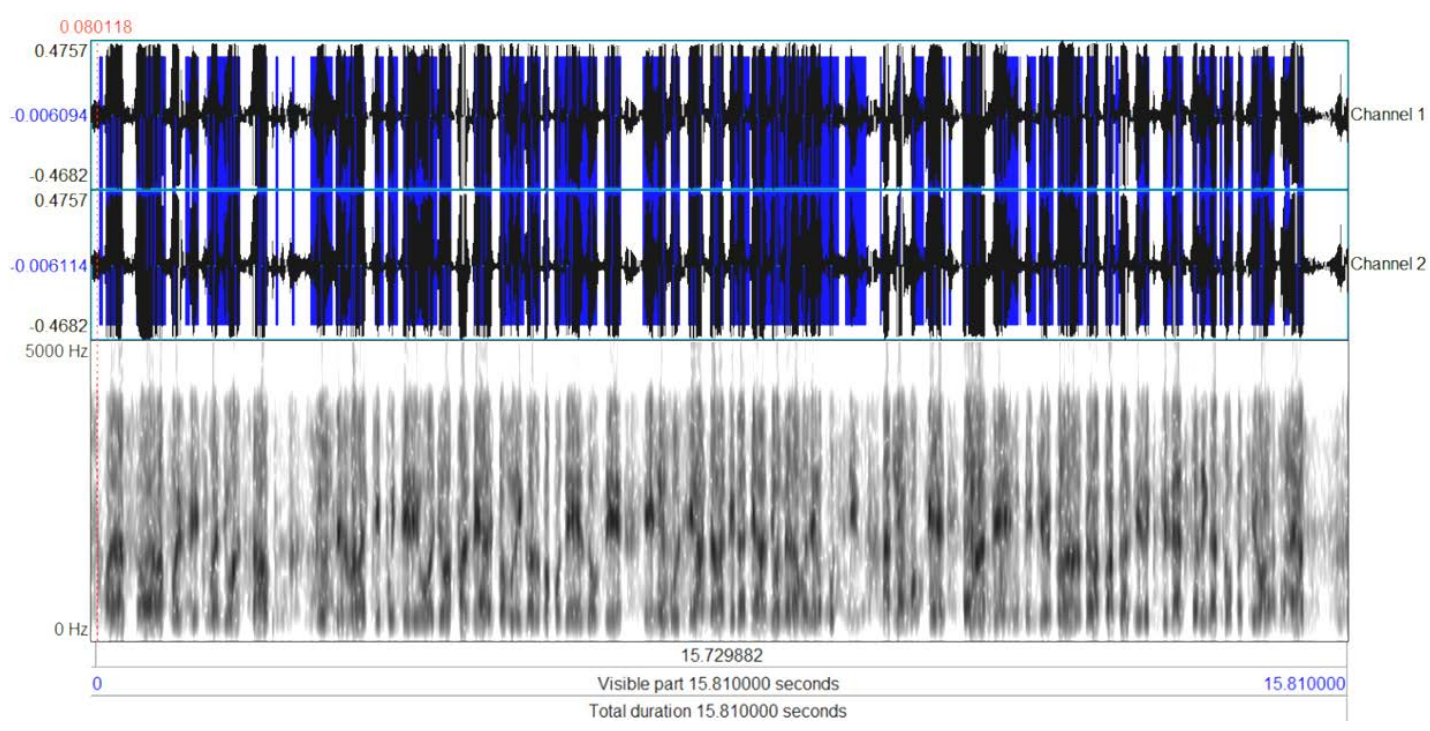

Imagem 3: Frequência de produção sonora do enunciado $b$

Fonte: dados dos pesquisadores.

Na Imagem 3, é representada uma sequência sonora detentora de uma alta frequência de produção, conforme podemos observar com a ajuda das colunas marcadas em azul que dizem respeito aos pulsos de produção acústica e representam uma quantificação da frequência e amplitude dos sons constituintes dos enunciados transcritos abaixo, que correspondem a um momento de um dos textos pertencentes ao nosso corpus:

b) Olha só. Ela foi vítima de um assalto. Trouxemos ela aqui pro interior de uma favela e tamo ligando pra poder resolver e negociar pela vida dela de uma melhor maneira possível. Até porque ela mesmo pediu implorando pela própria vida que fizesse essa ligação pra senhora. Correto?

Por outro lado, ocorre uma situação diferente no gênero golpe da recarga premiada. Nesse golpe, um criminoso se passa por um representante de uma empresa que fornecerá um prêmio de alto valor monetário ao suposto ganhador, a possível vítima do golpe. Durante a interação, o criminoso procura ludibriar a vítima, utilizando argumentos que visam a fazer com que o atendente transfira certa quantia em dinheiro para uma conta bancária fornecida por ele.

Assim, por simularem uma interação telefônica entre o representante de uma empresa, um profissional de telemarketing e um suposto ganhador de um prêmio, o sujeito comunicante produz enunciados em um ritmo menos acelerado que o criminoso do golpe do falso sequestro. Novamente, as coerções do contrato de comunicação ditam as normas que devem ser seguidas, já que uma situação de comunicação tida como uma conversa entre um representante de uma empresa e o ganhador de um prêmio não precisaria, normalmente, ser pronunciada em um ritmo mais acelerado do que uma conversa cotidiana. Na representação da Imagem 4, essa questão se torna mais esclarecida: 


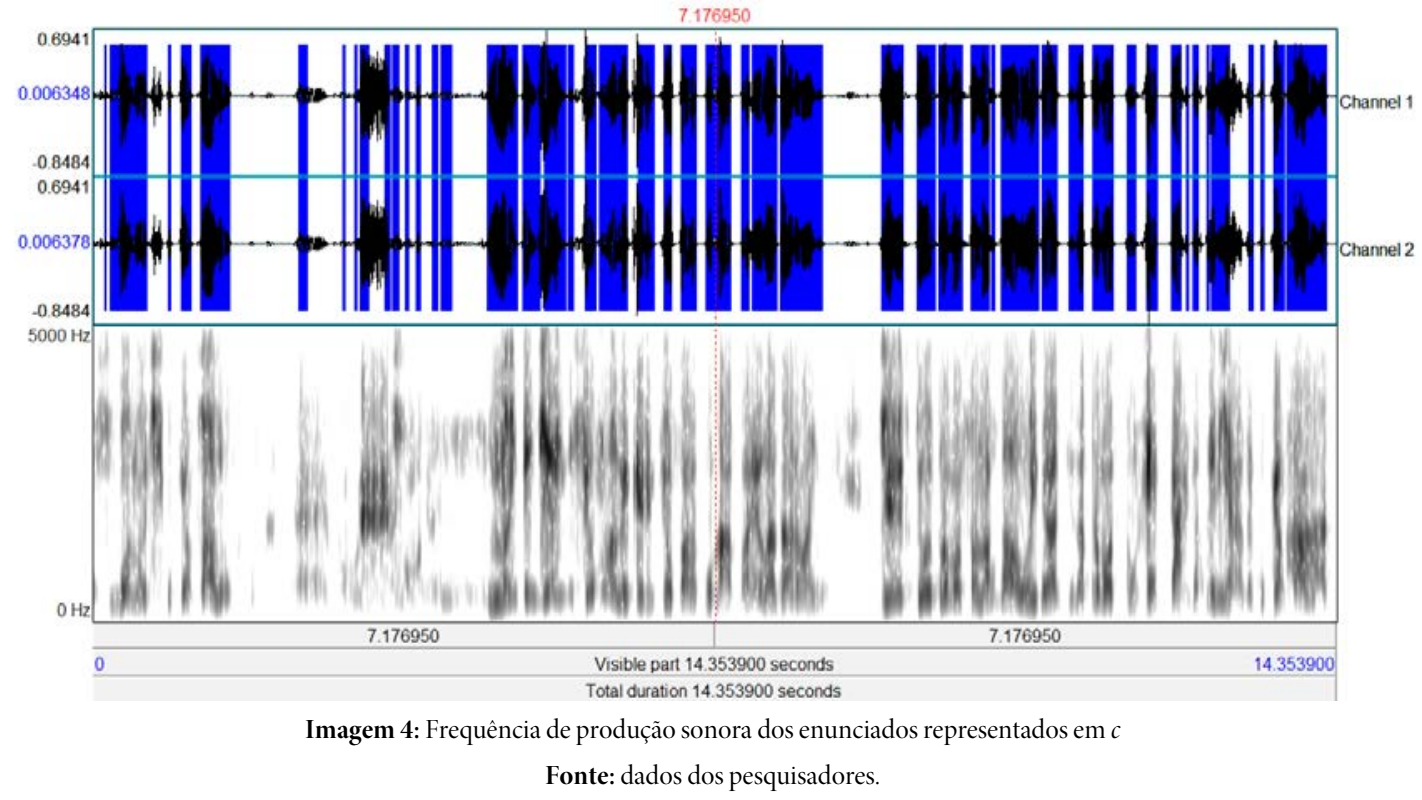

Observa-se que, diferentemente do que ocorre no espectrograma da Imagem 3, as marcações em azul são intercaladas por maiores espaços em branco, o que demonstra uma frequência de produção de pausas mais acentuada, o que culmina em um ritmo menos acelerado quando comparado ao enunciado relativo ao golpe do falso sequestro. Encontramos, nesse excerto, o recurso ao procedimento expressivo do "falar tranquilo", descrito por Charaudeau (2015), que pode favorecer a construção de um ethos de competência, relacionado ao profissionalismo do sujeito argumentante que se passa por um representante da empresa que fornecerá o suposto prêmio.

O espectrograma da Imagem 04 representa os seguintes enunciados:

c)

$E^{1}$ : alô, boa noite. Com quem eu falo?

$E^{2}$ : é com o. Com o Rodrigo.

$E^{1}$ : não entendi ainda o seu nome, querido. O senhor fala com o Rafael Lazaroni, diretor promocional da Oi ( ) na promoção Recarga Premiada, com quem eu falo?

Onde $E^{1}$ diz respeito ao enunciador 1 , no caso, o criminoso que se apresenta como um atendente de telemarketing da empresa de telefonia $\mathrm{Oi} \mathrm{e} \mathrm{E}^{2}$ diz respeito ao enunciador 2, ou à vítima que atendeu a ligação.

Partindo dos exemplos acima, podemos ver que um vocábulo ou enunciado proferido de forma mais enfática, com uma intensidade prosódica mais acentuada, parece favorer a construção do ethos de potência, de um criminoso cruel e violento, capaz de cumprir suas ameaças. Esse ethos parece ser realçado através do procedimento discursivo do "falar forte", já que o criminoso faz uso de uma intensidade mais acentuada para produzir seus enunciados.

Por fim, percebemos também que, dada a natureza comunicativa dos golpes da recarga premiada, o procedimento do "falar tranquilo" foi observado, já que a interação simulava uma conversa entre o representante de uma empresa e o ganhador de uma suposta premiação. Para isso, um ethos de competência, de um profissional devidamente credenciado pela empresa, foi construído visando à adesão maior por parte da possível vítima, o auditório do sujeito que argumenta.

Devido a essas observações, podemos perceber que determinados usos prosódicos, portanto, de natureza suprassegmental, podem auxiliar na construção de determinados ethé discursivos que contribuem para que o sujeito argumentante garanta sua legitimidade e credibilidade. Essas estratégias discursivas procuram garantir a adesão do auditório às teses levantadas pelo argumentante. 


\section{CONSIDERAÇÕES FINAIS}

O presente artigo é parte de uma pesquisa maior, desenvolvida, na Universidade Federal de Viçosa, com o apoio da Capes. A pesquisa original propôs-se a analisar e desvelar a argumentação utilizada por criminosos em golpes do falso sequestro e golpes da recarga premiada. Neste trabalho, em particular, procuramos demonstrar que determinadas características linguístico-discursivas, relacionadas a certas particularidades prosódicas, podem auxiliar na construção e na manutenção de determinados ethé discursivos. Conforme pudemos observar a partir dos espectrogramas analisados, em alguns argumentos, o criminoso, na vez de sujeito argumentante, faz uso de uma intensidade prosódica mais elevada, recurso que parece contribuir para construção e manutenção do ethos de potência, de um criminoso cruel, violento, assustador, capaz de cumprir suas ameaças. Além disso, observamos que, enquanto a produção rítmica no golpe do falso sequestro é mais acentuada, demonstrando o caráter rápido da produção dos enunciados nesse tipo de interação, nos golpes da recarga premiada ocorre o oposto e o ritmo aproxima-se ao da conversa cotidiana, o que contribui para a construção de um ethos de competência, relacionado ao profissionalismo do sujeito argumentante.

Após a observação dos nossos dados, portanto, pudemos notar que as características relacionadas ao tom, à intensidade prosódica dos enunciados e à frequência de produção sonora podem contribuir para construção e manutenção de alguns ethé discursivos que visam a garantir a legitimidade do argumentante e a credibilidade aos seus argumentos, o que auxiliaria no processo de adesão do auditório, o interlocutor. Com isso, baseado principalmente na Teoria Semiolinguística e nos postulados da Nova Retórica, este trabalho vincula-se aos estudos efetuados por Charaudeau (2015), Maingueneau (2008) e Galinari (2011) a respeito da possibilidade de determinadas características prosódicas auxiliarem na construção do ethos, não apenas procurando levantar uma hipótese, mas demonstrando, através da análise do material empírico, que, mesmo o nível suprassegmental, pode contribuir para a construção de sentidos diversos evidenciados pelo discurso.

\section{REFERENCIAS}

ARISTÓTELES. Retórica. 2. ed. Lisboa: Imprensa Nacional Casa da Moeda, 2005.

CHARAUDEAU, P. Identidade social e identidade discursiva, o fundamento da competência comunicacional. In: PIETROLUONGO, Márcia. (Org.). O trabalho da tradução. Rio de Janeiro: Contra Capa, 2009, p. 309 - 326.

Linguagem e discurso: modos de organização. São Paulo: Contexto, 2012.

O discurso político. São Paulo: Contexto, 2015.

FOULKES, P.; FRENCK, P. Forensic phonetics and sociolinguistics. In: MESTHRIE, R. (Ed.). The concise encyclopedia of sociolinguistics. Amsterdam: Pergamon, 1999. p. 329-332.

GALINARI, M. M. A polissemia do logos e a argumentação. Contribuições sofísticas para a análise do discurso. EID\&A - Revista Eletrônica de Estudos Integrados em Discurso e Argumentação, Ilhéus, n. 1, p. 93-103, nov. 2011.

LINHARES, J. Terror pelo telefone. Veja, São Paulo, p. 38-45, 21 fev. 2007. Disponível em: < http://veja.abril.com.br/210207/p_038.shtml >. Acesso em: 11 abr. 2015. 
MAINGUENEAU, D. Analisando discursos constituintes. Trad. Nelson Barros da Costa. Revista do Gelne, Fortaleza, v. 2, n. 2, p. 112,2000 .

. A propósito do ethos. In: MOTA, Ana Raquel; SALGADO, Luciana (Org.). Ethos Discursivo. Contexto, São Paulo: 2008. p.11-32.

MATEUS, M. H. M.; FALÉ, I.; FREITAS, M. J. Fonética e fonologia do português. Lisboa: Universidade Aberta, 2005.

PERELMAN, C.; OLBRECHTS-TYTECA, L. Tratado da argumentação: a Nova Retórica. São Paulo: Martins Fontes, 2005.

SILVA, W. P.; MELO, M. S. de S. As estratégias argumentativas em crimes de extorsão: uma análise de discursos patêmicos em golpes de falso sequestro. Diálogo das Letras, Pau dos Ferros, v. 02, n. 01, p. 374-39, jan./jun. 2013. 